7. Doyle A, Bhalla KS, Jones JM III, Ennis DM. Myocardial involvement in Rocky Mountain spotted fever: a case report and review. Am J Med Sci. 2006;332:208-10. http://dx.doi.org/ 10.1097/00000441-200610000-00009

8. Kularatne SA, Rajapakse RP, Wickramasinghe WM, Nanayakkara DM, Budagoda SS, Weerakoon KG, et al. Rickettsioses in the central hills of Sri Lanka: serological evidence of increasing burden of spotted fever group. Int J Infect Dis. 2013;17:e988-92. http://dx.doi.org/10.1016/j.ijid.2013.05.014

9. Kushawaha A, Brown M, Martin I, Evenhuis W. Hitch-hiker taken for a ride: an unusual case of myocarditis, septic shock and adult respiratory distress syndrome. BMJ Case Rep. 2013;2013. pii: bcr2012007155. http://dx.doi.org/10.1136/bcr-2012-007155

10. Solary J, Socolovschi C, Aubry C, Brouqui P, Raoult D, Parola P. Detection of Rickettsia sibirica mongolitimonae by using cutaneous swab samples and quantitative PCR. Emerg Infect Dis. 2014;20:716-8. http://dx.doi.org/10.3201/eid2004.130575

Address for correspondence: Pablo Revilla-Marti, Hospital Clinico Universitario Lozano Blesa, Avenida San Juan Bosco 15, Zaragoza 50009, Spain; email: pablorevillamarti@gmail.com

\section{Enteropathogenic Escherichia coli 080:H2 in Young Calves with Diarrhea, Belgium}

\author{
Damien Thiry, Marc Saulmont, Shino Takaki, \\ Klara De Rauw, Jean-Noël Duprez, \\ Atsushi Iguchi, Denis Piérard, Jacques G. Mainil
}

Author affiliations: University of Liège, Liège, Belgium (D. Thiry, S. Takaki, J.-N. Duprez, J.G. Mainil); Association Régionale de Santé et d'Identification Animales, Ciney, Belgium (M. Saulmont); Universitair Ziekenhuis Brussel, Brussels, Belgium (K. De Rauw, D. Piérard); University of Miyazaki, Miyazaki, Japan (S. Takaki, A. Iguchi)

DOI: https://doi.org/10.3201/eid2312.170450

Serogroup O80 was detected in $40 \%$ of 104 enteropathogenic Escherichia coli isolates from calves with diarrhea from 42 farms in Belgium during 2008-2015. These isolates harbored the eae- $\xi$ and $f l i C_{\mathrm{H}_{2}}$ genes, similar to the $\mathrm{O} 80$ attaching-effacing Shigatoxigenic $E$. coli isolates found in humans in France. This strain might be emerging.

$\mathrm{E}$ nteropathogenic and attaching-effacing Shigatoxigenic Escherichia coli (EPEC and AE-STEC) cause bloody diarrhea in humans and young calves. For clarity, we use the term AE-STEC instead of enterohemorrhagic E. coli, similar to a previous publication (1), to refer to STEC isolates from animals that produce attaching-effacing lesions. EPEC and AE-STEC that infect humans are diverse and comprise scores of serotypes (2); in contrast, most calf AE-STEC strains comprise a few serotypes, mostly O5:H-, O26:H11, O111:H-, and O118:H16 (3). The O26:H11 serotype is also the most common among calf EPEC. However, most serotypes that infect calves have not been identified (3). Therefore, during November 2008-June 2015, we conducted a study on 104 EPEC and 153 AE-STEC isolates collected from the feces or the intestinal contents of calves suffering diarrhea (1 isolate/calf) at the Association Régionale de Santé et d'Identification Animales in Ciney, Belgium. Isolates were screened by PCR for genes of the 10 most pathogenic and common calf and human O serogroups: O5, O26, O103, O104, O111, O118, O121, O145, O157, and O165. Confirming published results (3), 80\% (122/153) of AESTEC isolates and only $21 \%(22 / 104)$ of EPEC isolates tested positive for 1 of these (J.G. Mainil, unpub. data) (4). We sought to further characterize this collection of calf EPEC with unidentified O serogroups.

We submitted 9 calf EPECs with unidentified serogroups to the O-typing multiplex PCR platform (5); 6 of 9 EPEC isolates contained the O80 serogroup-encoding gene, and 3 belonged to 3 other O serogroups. We subsequently performed an O80 serogroup-specific PCR (5) of all $31 \mathrm{AE}-S T E C$ and 82 EPEC isolates with unidentified serogroups, along with one O80-positive E. coli strain and negative controls; 42 EPEC isolates and the O80-positive E. coli strain but no AE-STEC isolates or negative controls tested positive.

We further tested the calf EPEC isolates and $3 \mathrm{hu}-$ man Shiga toxin 2-encoding gene (stx2)-positive AESTEC O80 isolates from the STEC National Reference Center (Brussels, Belgium) by PCR for $f i C_{H 2}$ and eae- $\xi$ genes found in human AE-STEC O80 strains. For amplifying $e a e-\xi$, we used previously published PCR conditions (6), and for amplifying $f l i C_{H 2}$, we used primers $\mathrm{H} 2 \mathrm{~F}$ (5'-TGATCCGACATCTCCTGATG-3') and H2_R (5'-CCGTCATCACCAATCAACGC-3') and the following thermocycler conditions: initial denaturation at $94^{\circ} \mathrm{C}$ for $1 \mathrm{~min}$; 30 cycles of denaturation for $30 \mathrm{~s}$ at $94^{\circ} \mathrm{C}$, annealing for 30 $\mathrm{s}$ at $58^{\circ} \mathrm{C}$, and elongation for $1 \mathrm{~min}$ at $72^{\circ} \mathrm{C}$; and final elongation at $72^{\circ} \mathrm{C}$ for $2 \mathrm{~min}$. All 42 calf EPEC and 3 human AE-STEC isolates tested positive by both PCRs.

Among the 104 calf EPEC isolates, O80:H2 was frequently found ( $40 \%$ were PCR positive) and, thus, could be considered emerging. Indeed, the EPEC O80 isolates were isolated from calves from 42 farms. The yearly EPEC O80:H2 isolation rate varied from 12\% in 2009 to $40 \%-50 \%$ during $2010-2013$ to as high as $73 \%$ for the 
Table. Comparison of yearly isolation rates of EPEC O80:H2 and $\mathrm{O} 26$ from calves with diarrhea, Belgium, January 2009June $2015^{\star}$

\begin{tabular}{lccc}
\hline & \multicolumn{3}{c}{ EPEC } \\
\cline { 2 - 4 } Year & Total no. & O80:H2, \% & O26, \% \\
\hline 2009 & 17 & 24 & 12 \\
2010 & 19 & 47 & 5 \\
2011 & 12 & 50 & 33 \\
2012 & 9 & 33 & 22 \\
2013 & 15 & 47 & 20 \\
2014 & 20 & 25 & 25 \\
2015 & 11 & 73 & 9 \\
\hline Total & 104 & 41 & 16 \\
\hline${ }^{*}$ In 2008, only isolates collected in November and December were studied, \\
and 1 EPEC was identified. EPEC, enteropathogenic Escherichia coli. \\
\hline
\end{tabular}

first 6 months of 2015 (Table). In comparison, the rate for EPEC O26 serotype was 5\%-25\%. Although prevalence data before 2009 are lacking, EPEC O80 isolates have been found infrequently in animals: 8 in dead poultry $(7,8), 1$ in a piglet with diarrhea $(9), 1$ in a healthy cow (9), and 5 in lambs with diarrhea (10). However, even fewer AE-STEC O80 isolates have been found: 2 in healthy cattle (6); 1 in a calf with diarrhea in January 1987 (J.G. Mainil, unpub. data); and 1 in raw cow's milk cheese (9). According to the literature, the O80:H2 serotype might be emerging in France, where human cases of AE-STEC O80:H2 have been reported (9).

Molecular virulotyping results indicate that our calf EPEC O80 isolates appeared to be more closely related to human AE-STEC (because they all harbored eae- $\xi$ and $\mathrm{fli}_{\mathrm{H}}$ ) than to ovine and poultry EPEC O80 (which usually harbor eae- $\beta$ and $\left.f l i C_{H_{22}}\right)$ (J.G. Mainil, unpub. data) $(8,10)$. Further studies are needed to characterize these calf EPEC $\mathrm{O} 80: \mathrm{H} 2$ isolates, and the isolation rate of EPEC O80:H2 in calves with diarrhea must be tracked. Additional PCR virulotyping should be performed with our isolates to identify, if present, other EPEC-related virulence genes and extraintestinal E. coli-related virulence genes. Some genes could be located on plasmids, like those that were found in AESTEC O80:H2 patients with bacteremia and internal organ infections (9), although the infected calves from which our isolates were taken did not show evidence of septicemia before or after necropsy. The relationship among calf EPEC O80:H2 isolates (which are all independent isolates, not constituting a single strain until proven otherwise) and between calf and human isolates needs to be further characterized with pulsed-field gel electrophoresis and wholegenome sequencing. The prevalence of O80:H2 EPEC and AE-STEC in healthy cattle at slaughterhouses and farms in Belgium should be examined. Finally, we need to determine whether these calf EPEC O80:H2 isolates are true EPEC, AE-STEC derivatives that have lost stx genes, or AE-STEC precursors that could acquire stx genes in the future. This work will aid in the detection, prevention, and control of this potentially emerging pathogen.

\section{Acknowledgments}

The authors thank Maika Furukawa for her efficient technical support and Melha Mellata for helpful discussions.

The University of Liège provided financial support (Fonds Spéciaux de la Recherche, 2016-2018). S.T. is a trainee veterinary student from the University of Miyazaki, Japan, under the Japan Public-Private Partnership Student Study Abroad Program of the Japan Student Services Organization.

Dr. Thiry is an assistant professor at the Bacteriology Laboratory at the Faculty of Veterinary Medicine of the University of Liège. His areas of research are the identification of enteropathogenic and Shigatoxigenic Escherichia coli isolated from young diarrheic calves and bacteriophages as an alternative treatment for bacterial infections (Escherichia coli and Staphylococcus aureus) in cattle.

\section{References}

1. Piérard D, De Greve H, Haesebrouck F, Mainil J. O157:H7 and O104:H4 vero/Shiga toxin-producing Escherichia coli outbreaks: respective role of cattle and humans. Vet Res (Faisalabad). 2012;43:13. http://dx.doi.org/10.1186/1297-9716-43-13

2. Tozzoli R, Scheutz F. Diarrhoeagenic Escherichia coli infections in humans. In: Morabito S, editor. Pathogenic Escherichia coli: molecular and cellular microbiology. Norwich (UK): Horizon Scientific Press and Caister Academic Press; 2014.

3. Mainil JG, Fairbrother JM. Pathogenic Escherichia coli in domestic mammals and birds. In: Morabito S, editor. Pathogenic Escherichia coli: molecular and cellular microbiology. Norwich (UK): Horizon Scientific Press and Caister Academic Press; 2014.

4. Fakih I, Thiry D, Duprez JN, Saulmont M, Iguchi A, Piérard D, et al. Identification of Shiga toxin-producing (STEC) and enteropathogenic (EPEC) Escherichia coli in diarrhoeic calves and comparative genomics of O5 bovine and human STEC. Vet Microbiol. 2017;202:16-22. http://dx.doi.org/10.1016/ j.vetmic.2016.02.017

5. Iguchi A, Iyoda S, Seto K, Morita-Ishihara T, Scheutz F, Ohnishi M; Pathogenic E. coli Working Group in Japan. Escherichia coli O-genotyping PCR: a comprehensive and practical platform for molecular O serogrouping. J Clin Microbiol. 2015;53:2427-32. http://dx.doi.org/10.1128/JCM.00321-15

6. Blanco M, Blanco JE, Mora A, Dahbi G, Alonso MP, González EA, et al. Serotypes, virulence genes, and intimin types of Shiga toxin (verotoxin)-producing Escherichia coli isolates from cattle in Spain and identification of a new intimin variant gene $(e a e-\xi)$. J Clin Microbiol. 2004;42:645-51. http://dx.doi.org/10.1128/ JCM.42.2.645-651.2004

7. Schouler C, Schaeffer B, Brée A, Mora A, Dahbi G, Biet F, et al. Diagnostic strategy for identifying avian pathogenic Escherichia coli based on four patterns of virulence genes. J Clin Microbiol. 2012;50:1673-8. http://dx.doi.org/10.1128/ JCM.05057-11

8. Oh JY, Kang MS, An BK, Shin EG, Kim MJ, Kim YJ, et al. Prevalence and characteristics of intimin-producing Escherichia coli strains isolated from healthy chickens in Korea. Poult Sci. 2012;91:2438-43. http://dx.doi.org/10.3382/ ps.2012-02301

9. Soysal N, Mariani-Kurkdjian P, Smail Y, Liguori S, Gouali M, Loukiadis E, et al. Enterohemorrhagic Escherichia coli hybrid pathotype O80:H2 as a new therapeutic challenge. Emerg Infect Dis. 2016;22:1604-12. http://dx.doi.org/10.3201/eid2209.160304 
10. Cid D, Ruiz-Santa-Quiteria JA, Marín I, Sanz R, Orden JA, Amils R, et al. Association between intimin (eae) and $\operatorname{esp} B$ gene subtypes in attaching and effacing Escherichia coli strains isolated from diarrhoeic lambs and goat kids. Microbiology. 2001;147: 2341-53. http://dx.doi.org/10.1099/00221287-147-8-2341

Address for correspondence: Jacques G. Mainil, Bacteriology Laboratory, Department of Infectious Diseases, Faculty of Veterinary Medicine, Campus du Sart Tilman B43a, Quartier Vallée 2, Avenue de Cureghem 6, Université de Liège, 4000, Liège, Belgium; email: jg.mainil@uliege.be

\section{Incentives for Bushmeat Consumption and Importation among West African Immigrants, Minnesota, USA}

\author{
Emily Walz, David Wilson, Jacob C. Stauffer, \\ Danushka Wanduragala, William M. Stauffer, \\ Dominic A. Travis, ${ }^{1}$ Jonathan D. Alpern ${ }^{1}$
}

Author affiliations: University of Minnesota, Minneapolis, Minnesota, USA (E. Walz, W.M. Stauffer, D.A. Travis, J.D. Alpern); African Career, Education, and Resources, Inc., Brooklyn Park, Minnesota, USA (D. Wilson); Stillwater High School, Stillwater, Minnesota, USA (J.C. Stauffer); Minnesota Department of Health, St. Paul, Minnesota, USA (D. Wanduragala)

DOI: https://doi.org/10.3201/eid2312.170563

The knowledge, attitudes, and practices surrounding bushmeat consumption and importation in the United States are not well described. Focus groups of West African persons living in Minnesota, USA, found that perceived risks are low and unlikely to deter consumers. Incentives for importation and consumption were multifactorial in this community.

$\mathrm{B}$ ushmeat hunting and butchery are risk factors for zoonotic disease transmission (1-3). However, less is known about health risks to those who consume products that are already butchered when purchased. Bushmeat in this report refers to meat from wild African animals such as rodents, hooved animals, carnivores, primates, and bats (3).

Thousands of pounds of bushmeat are illegally imported into the United States annually (4), mostly from West

${ }^{1}$ These senior authors contributed equally to this article.
Africa (5). A previous study of bushmeat consumption by African immigrants in the United States described mixed perceptions regarding the risks and benefits of consuming bushmeat (5). Improved understanding of the complex social drivers of these practices is needed to better characterize risk and formulate communication strategies.

To identify the cultural perspectives and knowledge, attitudes, and practices surrounding bushmeat importation and consumption, we held focus groups with members of the Liberian community living in the Minneapolis-St. Paul area of Minnesota, USA. Minneapolis-St. Paul has the largest Liberia-born population in the United States, and ranks fifth in overall African populations in US metropolitan areas (6). Recognizing the history of stigmatization associated with increased risk for Ebola virus among persons from West Africa, we engaged a community-based organization to partner in the planning and execution of this study $(7,8)$. Creating a comfortable environment where participants share personal experiences and insights freely is a key tenet of focus group methodology (9); this partnership was essential in gaining trust and maintaining cultural sensitivity.

Inclusion criteria for participant selection included: 1) minimum age 18 years, 2) self-identification as West African, and 3) willingness to discuss bushmeat in a group setting. The partner organization recruited community members by using a combination of purposeful sampling and social media advertisement and facilitated 3 focus groups (10-12 participants, each for $90 \mathrm{~min}$ ) in January and February 2016; a designated research team member attended each session. A standard guide for questions was used for each session (online Technical Appendix, https://wwwnc. cdc.gov/EID/article/23/12/17-0563-Techapp1.pdf). The University of Minnesota Institutional Review Board approved this study.

Sessions were audio recorded and transcribed; participants were not identified. Nonverbal cues (i.e., gestures, emotions, points of hesitation, nods of agreement) and other participant interactions were added to the transcript by a notetaker. We analyzed the collected data by using a modified grounded theory method with inductive analysis as previously described (10). Two authors (E.W., J.D.A.) analyzed each transcript by using an open and selective coding approach. Subsequently, all transcripts were analyzed together by using axial coding further describing relationships among themes (Table); representative quotes from participants were selected to exemplify a relationship or common theme (9) (Table). We supported validity of findings by using member-checking, triangulation of findings with multiple sources, and peer debriefing (9). Many themes were repeated in all groups; however, this study was limited by inability to confirm that we had reached saturation of perspectives. According to Creswell, it is ideal 